\title{
UM CORPO EM PRESENÇA. UMa APROXIMAÇÃo A MARINA Abramović
}

\author{
Tomás N. Castro* \\ (Bolseiro UL/FAD, Universidade de Lisboa)
}

\begin{abstract}
fôsses tu um grande espaço e eu tacteasse com todo o meu corpo sôfrego e cego

Herberto Helder, Servidões
\end{abstract}

\begin{abstract}
So, what is a good work of art? It has that energy that tunes you into what is going on behind your back. Bruce Naumann always likes to say, "Art is a matter of life and death." It sounds melodramatic, but it is so true. If you take whatever you do as a matter of life and death, and if you are there one hundred percent, then things really happen. Less than one hundred percent is not good art. It's so hard to do it, but it is the only way. And this means no compromises.
\end{abstract}

"Marina Abramović on Performance Art"1

\section{I. "the public is like a dog: they sense the insecurity"}

No período 1973-74 Marina Abramović levou a cabo um conjunto de performances unificado tanto pela mesma preocupação artística, como

\footnotetext{
*tomas.castro@campus.ul.pt

Agradecemos ao Prof. Doutor Carlos João Correia, em cujo curso de Filosofia da Arte apresentámos este ensaio, ao Prof. Doutor José Miranda Justo, que nos despertou para o pensar destas questões, assim como ao júri do Prémio Prof. Doutor Joaquim Cerqueira Gonçalves 2013 pela confiança em nós depositada.

${ }^{1}$ Os depoimentos citados no presente trabalho foram retirados de "Marina Abramović on Performance Art", in Marina Abramović, The Artist is Present, ed. Klaus Biesenbach (New York: The Museum of Modern Art, 2010), 211.
}

Philosophica, 42, Lisboa, 2013, pp. 189-198. 
pelo seu nome: Rhythms. A primeira obra, Rhythm 10, foi apresentada durante uma hora no Museo d'Arte Contemporanea Villa Borghese, Roma, na qual a artista, depois de ligar um gravador de som, faz o seguinte: "I take the first knife and stab in between the fingers of my left hand as fast as possible." Anteriormente prescrevera: "I place 20 knives [uma versão anterior da performance, no Edinbugh Festival, fora realizada com 10 facas] of different sizes and shapes on the paper." Após cada corte muda a faca e retoma a actividade. Depois de ter utilizado todas as facas, ou seja, depois de se ter cortado vinte vezes, ouve a gravação da primeira parte da performance, depois concentra-se ("I concentrate") e repete o que até então fizera, seguindo a mesma ordem e cortando-se nos mesmos lugares. Abramović, no croquis da performance, expõe a sua intenção: "In this performance the mistakes of time past and the time present are synchronized." Finalmente ouve a gravação dos dois momentos, dois ritmos justapostos, e a performance termina com a sua saída. ${ }^{2}$

Rhythm 5 data de 1974 e foi realizada em Belgrado, quando Marina Abramović ainda vivia nos Balcãs. "I construct a five-pointed star (the construction is made in wood shavings soaked in 100 liters of petrol)." Depois de acender a estrela, corta o cabelo e as unhas dos pés e das mãos e atira-os para a estrela. Entra no espaço vazio dentro da estrela ardente e deita-se no chão. A performance terminou ao fim de uma hora e meia, com a artista a ser assistida por um médico que se encontrava na audiência, uma vez que perdera a consciência acidentalmente, devido à falta de oxigénio causada pela combustão que a rodeava. ${ }^{3} \mathrm{Em}$ Rhythm 2 o leitmotiv foi a perda de consciência, já não involuntária, mas voluntariamente, através da ingestão de fármacos, que tanto levaram o corpo da performer a fazer movimentos que não controlava, como a estar completamente imobilizada ou a perder a memória do sucedido; em Rhythm 4 Marina Abramović acaba por perder a consciência devido às pressões extremas causadas por um "air blower" que lhe projecta quantidades maciças de ar na face. A última obra deste ciclo (e uma das mais célebres de Abramović) testou todos os limites, como se depreende da descrição que dela fez a artista: "Instructions. / There are 72 objects on the table that one can use on me as desired. / Performance / I am the object. / During this period I take fully responsibility." Da lista de objectos em cima da mesa, destacam-se os dois primeiros, uma arma ("gun") e uma bala ("bullet"). A performance aconteceu em Nápoles, no Studio Morra, durante seis horas. À medida que o tempo foi passando, os comportamentos da audiência tornaram-se cada vez mais agressivos, levando a uma atmosfera de grande tensão, admitida a possibilidade de a arma carregada ser utilizada. $\mathrm{Na}$

\footnotetext{
2 "Rhythm 10" in Abramović, The Artist Is Present, 60.

3 "Rhythm 5" in Abramović, The Artist Is Present, 64.
} 
descrição deste último Rhythm a autora conclui: "I conclude my research on the body when conscious and unconscious." 4

Em 2002, no rescaldo do traumático "9/11", Marina Abramović mostra-se totalmente vulnerável em nudez integral, física e social, vivendo publicamente durante 12 dias na Sean Kelly Gallery, Nova Iorque, onde a sua actividade se resumiu a uma instalação pública, diante dos olhos da audiência, em abstinência de comida, bebendo água, urinando, tomando três banhos por dia, não lendo nem escrevendo e não falando uma performance intitulada The House with the Ocean View. Sem palavras nem possibilidade de interacção verbal com os espectadores presentes estabeleceu-se, no entanto, um clima de máxima intimidade, possibilitada por uma narrativa visual de conteúdo fortíssimo. ${ }^{5}$

Mais problemática no que diz respeito à discussão filosófica é a empresa chamada Seven Easy Pieces levada a cabo em 2005 no Guggenheim Museum, Nova Iorque, que consistiu na re-performance em sete noites consecutivas de cinco performances que fizeram história na tradição performática (entre as quais a Seedbed de Acconci, adaptada à anatomia feminina) ${ }^{6}$ assim como de duas obras de autoria própria (Lips of Thomas de 1975 e Entering the Other Side, uma obra inédita). Ciclo este que chamou ao debate questões como a legitimidade da re-performance e a natureza ontológica da própria (re-)performance.

\section{Campos de interferências}

A performance é um fenómeno cujos trâmites são de difícil circunscrição, quer no que diz respeito à história da arte (a emergência a partir do teatro e da dança) como na especulação filosófica (a ontologia da obra de arte). A consideração da dança fornece-nos uma utensilagem conceptual que se mostra útil nesta discussão. ${ }^{7}$

\footnotetext{
4 "Rhythm 0" in Abramović, The Artist is Present, 74.

5 "The House with the Ocean View" in Abramović, The Artist is Present, 180-185; vd. website da galeria disponível em http://www.skny.com/exhibitions/2002-11-15_marina-abramovi (acesso 01/10/2013). Esta performance partilha de alguns aspectos, como a exposição pública e a crítica sócio-política manifestas, com uma performance de 1997, Balkan Baroque, que, dada a extensão deste trabalho, não nos será possível abordar; vd. Michael Rush, New Media in Art (London: Thames \& Hudson, 2005), 146-50.

${ }^{6}$ Bruce Nauman, Body Pressure, 1974; Vito Acconci, Seedbed, 1972; Valie Export, Action Pants: Genital Panic, 1969; Gina Pane, The Conditioning, 1973; Joseph Beuys, How to Explain Pictures to a Dead Hare, 1965. Uma descrição detalhada do ciclo performático pode ser consultada na página http://pastexhibitions. guggenheim.org/abramovic (acesso 01/10/2013).

${ }^{7}$ Daremos conta de alguns pontos expostos por Carroll na sua argumentação acerca
} 
Uma primeira perspectiva é a da Antiguidade Clássica, nomeadamente Platão (as considerações sobre as artes na República) e Aristóteles (Poética, 1447a25), segundo a qual a dança está associada a contextos de apresentações teatrais ou dramáticas. A partir desta concepção, autores como Weaver e Noverre defenderam aquilo que poderemos chamar uma teoria da dança de inspiração aristotélica, utilizando a teoria da $\mu \mu \eta \dot{\sigma ı \varsigma}$ do Estagirita para definir "representação" como "imitação". Se para Aristóteles a essência (ov̉oíl $\alpha$ ) da tragédia ou de um drama era a imitação de acções $(\pi \rho \tilde{\alpha} \xi 1 \zeta)$, podemos com isto considerar também a dança como uma espécie de imitação - integrando a dança no sistema das artes, estes autores estão, assim, a colocar como seu fim último a beleza da imitação, ${ }^{8}$ o que acaba por corresponder a uma consideração da dança qua (imitação) mas não uma dança quae (o objecto em si), utilizando um vocabulário medieval.

Andre Levinson, por outro lado, aproxima-se do formalismo de Clive Bell e de Roger Fry, defendendo a importância da "forma" (coreográfica, neste caso) na concepção da dança. ${ }^{9}$ É possível, também, definir uma perspectiva de fundo kantiano, a partir da matriz do desinteresse estético, advogando para a dança uma emancipação face às teleologias das teorias anteriores. Mas talvez a mais evidente seja a teoria da expressão que, partindo dos antecedentes miméticos aduzidos de Aristóteles, chama para a dança a expressão de sentimentos e emoções, da qual é exemplo Monroe Beardsley. ${ }^{10} \mathrm{O}$ chamado período "pós-histórico" (a partir da declaração de Arthur C. Danto), que outros preferem chamar de "pós-modernismo", comporta outra espécie de problemas, como aqueles mostrados pelos jogos e as semelhanças familiares de Ludwig Wittgens-

da consideração filosófica da dança: Noël Carroll, "Dance", in The Oxford Handbook of Aesthetics, ed. Jerrold Levinson (Oxford: Oxford University Press, 2005), 583-593.

${ }^{8}$ «[...] the Excellency of this Art does or ought to consist: the Beauty of Imitation», John Waever, An Essay towards a History of Dancing (London: J. Tonson, 1712), 159 apud Carroll, "Dance", 585; cf. Jean-Georges Noverre, Letters on Dancing and Ballet, trad. C. W. Beaumont (Brooklyn, NY: Dance Horizons, 1966).

${ }^{9}$ Andre Levinson, "The Spirit of the Classical Dance", in Dance as a Theatre Art, ed. S. J. Cohen (New York: Dodd, Mead, 1974); cf. Clive Bell, Art (Oxford: Oxford University Press, 1987) e Nigel Warburton, The Art Question (London: Routledge, 2003), 9-35.

${ }^{10}$ Monroe Beardsley, “What is Going On in a Dance?", Dance Research Journal 15: 31-7. Faz lembrar a teoria da expressão de emoções de Collingwood, o qual, no entanto, não estamos certos se aceitaria tout court a dança como uma arte (e não como um ofício) tão legítima como a pintura, por exemplo. Vd. R. G. Collingwood, The Principles of Art (Oxford: Oxford University Press, 1958) e Warburton, The Art Question, 37-62. 
tein nas suas Investigações Lógicas: "não penses, olha!" 11 - ora, uma vez que a própria prática artística da dança, e da performance, como vimos, passou a comportar manifestações em tudo iguais aos demais gestos e movimentos do dia-a-dia, como as distinguir? Será necessário convocar uma teoria como seja a institucional da arte de George Dickie ou a intencional-histórica de J. Levinson para esclarecer a natureza destas artes?

A tónica do trabalho de Abramović é o questionamento dos valores da corporeidade do artista. O ciclo Rhythms expressa bem isto, sendo difícil não colocar em causa o papel do corpo e os seus limites, testados e tentados nas performances. Sendo em primeiro lugar a matéria-prima do trabalho artístico, é ao mesmo tempo sujeito e objecto, daí que nos pareça possível falar da auto-reflexividade como constituição essencial da performance. Mesmo quando é uma intencionada "passividade" que se coloca em causa - como o deixar-se manipular por outrem ou expor-se na sua quase-totalidade - é um deixar-se acontecer premeditado e previamente pensado. Ao carácter improvisado ou aleatório, possibilitado pelas estruturas abertas na construção destas performances, opõe-se o seu cariz marcadamente intelectualizado, ainda que numa reflexão de resultados imprevisíveis sobre as semânticas da contingência. Aliás, se há coisa que a prática performativa de Abramović não esconde, é a assunção de uma agenda clara: existe um desvelar de um conteúdo crítico patente nas demarcações sócio-políticas que enformam as suas performances (por exemplo, as já citadas The House with the Ocean View ou Balkan Baroque).

Constitui-se o corpo, então, como um campo de interferências, ou melhor, um veículo passível de causar interferências. Daí que autores como Louppe falem de uma "poética do corpo" ", uma vez que este corpo e a sua "organicidade" são susceptíveis de constituírem significação. Deste modo, acrescenta-se à função orgânica do corpo uma simbólica, ou até um âmbito semiológico. Aplica-se bastante bem a metáfora de Harold Rosenberg que Arthur C. Danto gosta de citar: "the scene of performance

${ }^{11}$ Investigação Filosófica $n .^{\circ} 66$ in Ludwig Wittgenstein, Tratado Lógico-Filosófico e Investigações Lógicas, trad. M. S. Lourenço (Lisboa: Fundação Calouste Gulbenkian, 2011), 227; cf. Warburton, The Art Question, 65-85.

12 «Definiu-se a poética como o estudo das motivações que favorecem uma reacção emotiva a um sistema de significação ou de expressão. [...] A função poética tem a particularidade de provocar de forma imanente a intervenção dupla de um ponto de vista artístico (um sujeito, hipotético ou não, do acto criador) em estreita relação com a sensibilidade do interlocutor, que espera tocar no âmago das reacções estéticas (a que chamarei frequentemente estesias, como factor de sensibilização que precede toda e qualquer conceptualização construtiva).» Laurence Louppe, Poética da Dança Contemporânea, trad. Rute Costa (Lisboa: Orfeu Negro, 2012), 28. 
replaced the canvas as an arena for artistic action"13 - o corpo-arena, campo de forças em tensão, espaço privilegiado de expressão e simultaneamente de diálogo com um Outro. ${ }^{14}$ Este campo de relação estabelecido não é uma folha em branco, mas sim uma propriedade inerente à nossa constituição biológica, utilizada como meio de conhecimento e de sensação, uma porta de desvelamento estético (no sentido etimológico de

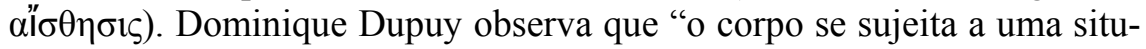
ação próxima do vazio [...] Encontra-se numa espécie de ausência, de silêncio de onde tudo pode surgir" - o que é o reconhecimento da necessidade de criar um espaço de diálogo partilhado, onde o sujeito expresso se constitua sensação para um outro. ${ }^{15}$

O corpo como materialização conceptual expressiva, como explica RoseLee Goldberg,

Tendo em conta que a arte conceptual implicava a experiência do tempo, do espaço e do material, e não a sua representação na forma de objectos, o corpo tornou-se o meio de expressão mais directo. A performance representava, assim, o meio ideal para materializar os conceitos de arte, e, como tal, proporcionava uma forma de aplicação prática dessas teorias. ${ }^{16}$

É uma resposta eficaz quando há demasiadas semelhanças familiares ou quando vacilam as provas páticas, já que se apresenta diante de nós tal

${ }^{13}$ Arthur C. Danto, "Danger and Disturbation: The Art of Marina Abramović", in Abramović, The Artist is Present, 29; cf. Arthur C. Danto, What Art Is (New Haven: Yale University Press, 2013), 11.

${ }^{14}$ «[...] escolher o corpo e o movimento do corpo como campo de relação com o mundo, como instrumento de saber, de pensamento e de expressão. [...] $\mathrm{O}$ principal aspecto a ter em conta é trabalhar, em primeiro lugar, as condições orgânicas dessa emergência poética [confiar no carácter «lírico» do orgânico, sem por isso lhe atribuir uma estética ou uma formatação precisas]. Uma vez tomada esta opção fecunda, o corpo tornar-se-á uma admirável ferramenta de conhecimento e de sensações.» Louppe, Poética, 69.

${ }^{15}$ Dominique Dupuy, "Le corps émerveillé", Marsyas 16 (Décembre 1990): 31-33 apud Louppe, Poética, 70. «Toda a obra de arte é um diálogo. «Centrada no destinatário, ela [a função poética] visa uma expressão directa da atitude do sujeito sobre aquilo a que este se refere.» Essa expressão da atitude do sujeito [...] põe em jogo uma dinâmica das atitudes do sujeito, tendo como referente o campo comum de experiência com o Outro que é a proposta da Obra de arte.» Louppe, Poética, 28; citação de Roman Jakobson, Essais de linguistique générale (Paris: Minuit, 1965), 214; cf. Gérard Genette, Esthétique et poétique (Paris: Seuil, 1992), 8.

${ }^{16}$ RoseLee Goldberg, A Arte da Performance: do Futurismo ao Presente, trad. Jefferson Luiz Camargo e Rui Lopes (Lisboa: Orfeu Negro, 2012), 194. 
como é, podemos vê-lo e não é possível ignorar o seu sofrimento. ${ }^{17}$ É desta lógica da empatia que, no fundo, Abramović se ocupa.

\section{III. "The performance is really about presence."}

Afirma ainda Marina Abramović: "If you escape presence, your performance is gone. It is always you, the mind, and the body." Em 2010 esteve patente no MoMA uma exposição retrospectiva de Marina Abramović chamada The Artist Is Present. Nos termos da sinopse do museu, uma "performance retrospective" na qual, para além da re-performance de um conjunto de obras históricas por jovens artistas instruídos pela própria criadora, teve lugar - desde o primeiro ao último dia da exposição, durante todo o horário de abertura - uma performance com o mesmo nome da exposição. Foi a performance mais longa que Abramović alguma vez fez e foi extensivamente registada fotograficamente e em documentário homónimo. ${ }^{18}$ Podemos resumi-la em termos simples: durante o horário de abertura do museu, no Marron Atrium, o visitante encontrava delimitado no chão um quadrado amplo, com projectores a iluminarem-no; no centro estava uma mesa, com duas cadeiras, uma em frente da outra; Abramović estava sentada em uma das cadeiras, imóvel (nos limites do possível), estando a outra cadeira à disposição do espectador-participante, que se podia sentar e olhar para a artista; cada vez que alguém se sentava ${ }^{19}$, a artista abria os olhos e focava-se na pessoa, olhando nos seus olhos, o que levou naturalmente a diferentes reacções de quem assistia, perante um contacto visual tão intenso; esta sequência repetia-se ad infinitum, e a performance continuou até ao fecho da exposição. Como se isto não bastasse, a performer acrescentou: "In The Artist Is Present I perform every day for three months. And I would like somehow to find a system so the performance would become life. That it actually becomes just timeless."

A tónica neste último trabalho de Abramović deve ser colocada nos valores temporais colocados em questão. Por um lado, esta performance insere-se numa linha de continuidade com anteriores produções, nas quais a resistência física levada ao limite tinha sido testada de inúmeras formas,

17 «The audience understands through seeing. It suffers with the suffering of the performer.» Danto, "Danger and Disturbation", 33.

${ }^{18}$ Consulte, por exemplo, 1566 fotografias tiradas pelo fotógrafo Marco Anelli em http://www.flickr.com/photos/themuseumofmodernart/sets/72157623741486824 ou também em http://www.repubblica.it/speciali/arte/2013/05/13/foto/1_emozione in_una_lacrima_ritratti_di_fronte_a_marina_abramovic-58714153/1/?ref=fbpr\#1 (acesso 01/10/2013). Para o filme, vd. Bibliografia.

${ }^{19}$ No caso de Arthur C. Danto, em cadeira de rodas, removeram a cadeira do recinto e foi deslocado. 
assim como as capacidades de resistência dos espectadores. Mas, se em produções como Rhythms e The House with the Ocean View era uma experiência no tempo que nos fornecia uma chave hermenêutica, em The Artist Is Present é o próprio tempo que é trabalhado, o "hic et nunc", ao qual o tempo passado e o futuro são estranhos, apenas e absolutamente só o presente (haverá aqui alguma reminiscência de Agostinho, Confessiones XI?) - esse agora que escapa.

A questão da re-performance no caso de Abramović (Seven Easy Pieces, as re-performances na exposição The Artist Is Present) pode ser equacionada lado a lado com a performance The Artist Is Present, que parece reiniciar-se sempre que cada pessoa se senta na cadeira. Podemos legitimar a re-apresentação de uma obra fazendo duas concessões: assentindo que uma pessoa pode ser substituída por outra, ou seja, permitir um novo performer (talvez um pouco como no teatro se concede uma distinção entre papel e actor, sendo que o agente não desvirtua o objecto), e aceitar que há uma experiência e efeito primordiais que não serão alvo de uma mera reprodução mas constituir-se-ão sim como um acontecimento novo e original, uma vez que a performance continuará a constituir-se como novidade para um público no qual ainda não foram suscitadas determinadas experiências estéticas ou, como propõe Danto, a causar a sensação como aconteceu na audiência primordial. ${ }^{20}$

A presença é a expressão empática que o corpo tem para apresentar. Hoje a arte confronta-se com um (falacioso) tudo-é-possível, não interessando ao certo quais as ideias ou os meios empregues para as veicular ${ }^{21}$, confunde e deixa-se confundir com os demais objectos e gestos quotidianos, ou ainda nega um sentido ou toda a espécie de descrições e narrativas estruturantes que possam conferir chaves hermenêuticas. Há, contudo, uma poderosa matéria-prima que não só invalida as tentativas herméticas como as desvela. Marina Abramović é, a nosso ver, um contributo importante para a prática da performance, assim como para a compreensão da arte "pós-moderna" (ou dos movimentos que se seguiram à arte conceptual): nela vemos emergir um conjunto de valores corporais relacionais - um sujeito, o outro e um espaço de relação/objecto criado -, cuja estrutura (essencialmente triádica) é poética, possibilita uma experiência e uma relação de significação, nomeadamente uma poiética ou uma interpretação. Muito recentemente, contrariando um pessimismo vigente na filosofia da arte, Arthur C. Danto adverte para uma possibilidade de dar definições: "the artist finds ways to embody the idea in a sensory medium.",22

${ }^{20}$ Danto, "Danger and Disturbation", 30.

21 «Today art can be made of anything, put together with anything, in the service of presenting any ideas whatsoever.» Danto, What Art Is, 128.

22 Danto, What Art Is, 123. 


\section{Bibliografia}

Marina Abramović: the Artist is Present. Realização de Matthew Akers. Show of Force LLC \& Mudpuppy Films INC, 2011. 102 min.

Anderson, Laurie. "Marina Abramović", BOMB 84 (Summer 2003).

Auslander, Philip. "The Performativity of Performance Documentation", PAJ: A Journal of Performance and Art 84, V. 28, n. 3 (September 2006).

Burton, Johanna. "Repeat Performance. Johanna Burton on Marina Abramović's Seven Easy Pieces", Artforum 44, 5 (January 2006).

Danto, Arthur C. "Sitting With Marina". The Stone [The New York Times blog], 23 May 2010, disponível em http://opinionator.blogs.nytimes.com/2010/ 05/23/sitting-with-marina (acesso 01/10/2013).

Danto, Arthur C. "On Art, Action and Meaning". The Stone [The New York Times blog], 3 June 2010, disponível em http://opinionator.blogs.nytimes. com/2010/06/03/on-art-action-and-meaning (acesso 01/10/2013).

Gayford, Martin. "Marina Abramović: Just How Much Pain Can One Body Take?", Times, 29 June 2009.

Goy, Bernard. "Marina Abramović", Journal of Contemporary Art, Inc. 3 (June 1990).

La Rocco, "Claudia, Some at MoMA Show Forget 'Look but Don't Touch"'. The New York Times, 16 April 2010.

Rose, Heather. "Sitting with Marina" in Art \& Australia V. 49, n. 3 (2012): 470-475 .

Smith, Roberta. "Where Seeing Is Not Only Believing, but Also Creating," The New York Times, 22 November 2002.

Tóibin, Colm. "Still drama: Marina at MoMA", The New York Review of Books, 21 April 2010.

Westcott, James. When Marina Abramovic Dies. Cambridge, Mass.: The MIT Press, 2010.

\section{RESUMO}

Descrevendo algumas performances de Marina Abramović, este ensaio procura fornecer um possível enquadramento filosófico para esta forma de arte. O âmbito da presença em Abramović é esclarecido utilizando algum vocabulário proveniente de uma certa poética do corpo na reflexão sobre a corporeidade, surgindo questões ontológicas na performance quando se pensa a possibilidade de re-performance.

Palavras-chave: Manina Abramović; filosofia da performance; estética; poética do corpo. 


\begin{abstract}
Describing some of Marina Abramović's performances, this essay aims to provide one possible philosophical framework in what concerns this form of art.

The scope of presence in Abramovic is enlightened by employing some vocabulary from a certain body poetics into the embodiment reflection, and ontological issues in performance come out when thinking about re-performance possibilities.
\end{abstract}

Keywords: Marina Abramović; philosophy of performance; aesthetics; body poetics. 